Macedonian Pharmaceutical Bulletin, 66 (Suppl 1) 209 - 210 (2020)

Online ISSN $1857-8969$

UDC: 628.4.046:005.936.5(497.113)

DOI: 10.33320/maced.pharm.bull.2020.66.03.104

Short communication

\title{
Attitudes and pracitce of pharmacists in pharmaceutical waste management - a pilot study in the city of Novi Sad
}

\author{
Svetlana Stojkov*, Nataša Jovanović Lješković, Milan Ilić, Jovana Vasiljković, \\ Slobodan Gigov
}

University Business Academy in Novi Sad, Faculty of Pharmacy, Trg mladenaca 5, 21000 Novi Sad, Serbia

\section{Introduction}

Development of pharmaceutical industry and constant improvement of healthcare systems have significantly increased availability of drugs worldwide. These phenomena, together with presence of consumerism in all segments of society, undoubtedly lead to increased procurement and use of medicines. Furthermore, this cause continuous increase in production of drugs globally (IMS institute, 2017), health complications as a result of inadequate drug use, and presence of pharmaceuticals in our environment with numerous ecological and health consequences (WHO, 2011). Pharmacists, as experts for medicines, have significant responsibility for health of the whole society, being involved in scientific research and development of new drugs, production of medicines and their distribution, patient counselling on proper drug, safe storage of drugs, and finally, appropriate pharmaceutical waste disposal.

Preservation of environment requires interdisciplinary and intersectoral collaboration on global and local level.

The aim of this paper is to show results of the collaboration project of the Faculty of Pharmacy, the Faculty of Law for Commerce and Judiciary, both members of University Business Academy in Novi Sad and local government of Novi Sad and comprehensive analysis of the pharmaceutical waste management process in the territory of Municipality of Novi Sad.

\section{Materials and methods}

Sectional study was conducted in pharmacy chains and individual community pharmacies in Municipality of Novi Sad by specially designed questionnaire. The questionnaire consisted of 12 questions, out of which two were open-ended questions and ten were closed-ended questions. Participation in this research was voluntary and anonymous.

\section{Results and discussion}

87 community pharmacists from Municipality of Novi Sad participated in this research. Average length of pharmacists working experience is 13 years. Amongst total number of respondents in this research, $16.1 \%$ had postgraduate degree and $29.9 \%$ of them were at the position of pharmacy manager. Most of pharmacists $(89.6 \%)$ provide information about safe and proper disposal of unused medicines in households to their patients, $37.9 \%$ of pharmacists

\footnotetext{
* slobodan.gigov@ faculty-pharmacy.com
} 
provide such information in every appropriate situation, and $51.7 \%$ of them do this at the request of the patient. About $10 \%$ of respondents do not provide these information to patients. Most of respondents stated that the information about safe disposal of unused drugs from households are required several times in a month $(36.8 \%)$. $34.5 \%$ of pharmacists said that they provide such information several times in a year, $16.1 \%$ of them do it every day, while $12.6 \%$ of pharmacists stated that their patients do not ask for information about unused drugs disposal. According to previous study in this region, knowledge and habits of citizens of Novi Sad regarding pharmaceutical waste disposal are not satisfactory - over $85 \%$ of respondents dispose it as communal waste (Kusturica et al., 2012), which is higher rate than in recent study from Poland, where $68 \%$ of drugs end up in communal waste and sewage (Rogowska et al., 2019).

Almost all of respondents (98.9\%) consider that pharmacists are competent for providing information about appropriate pharmaceutical waste disposal, and $96.6 \%$ of them stated that unused drugs and expired medicines belong to hazardous waste. Regarding question whether community pharmacies have to receive unused and expiry medicines from citizens, $13.8 \%$ of pharmacists gave negative answer, $3.4 \%$ of them were not sure, and $5.8 \%$ of them do not know the answer. Different level of knowledge of pharmacists about this topic result in various practice in pharmaceutical waste management in community pharmacies in Serbia (Stojkov et al., 2018). Most of pharmacists, 95.4\% of them, consider that there is a need for education about safe pharmaceutical waste disposal. According to the results of this study, $71.3 \%$ of respondents would attend such education, $23.0 \%$ of them responded "perhaps", while $5.7 \%$ said they would not attend education on this topic.

\section{Conclusion}

In order to reach high standards in pharmaceutical waste disposal collaborative environment including citizens, healthcare professionals and media should be improved. Activities in this process should start with education of citizens and continuing professional development of pharmacists, which would result in appropriate pharmaceutical waste management among citizens and pharmacists.

\section{References}

IMS institute, 2017. Global Use of Medicines Outlook to 2017. Available at:

https://www.jhsph.edu/research/centers-andinstitutes/center-for-drug-safety-and-

effectiveness/training/seminar-

series/Murray_Aikten.pdf (Last accessed: March 2019).

Kusturica, M.P., Sabo, A., Tomic, Z., Horvat, O., Solak, Z., 2012. Storage and disposal of unused medications: knowledge, behavior, and attitudes among Serbian people. Int. J. Clin. Pharm. 34, 604610. Available at: https://doi.org/10.1007/s11096012-9652-0.

Rogowska, J., Zimmermann, A., Muszynska, A., Ratajczyk, W., Wolska, L., 2019. Pharmaceutical household waste practices: preliminary findings from a case study in Poland. Environmental Management 64, 97-106.

Stojkov, S., Marinkovia, V., Manojlovia, J., 2018. Experiences during implemantation and differentation of regulations on pharmaceutical waste in pharmacies praxis. International Journal Advanced Quality 46(2), 2.

WHO, 2011. Pharmaceuticals in Drinking-water WHO/HSE/WSH/11.05. Available at: http://www.who.int/water_sanitation_health/publicati ons/2011/pharmaceuticals 20110601.pdf.

Last accessed: March 2019. 